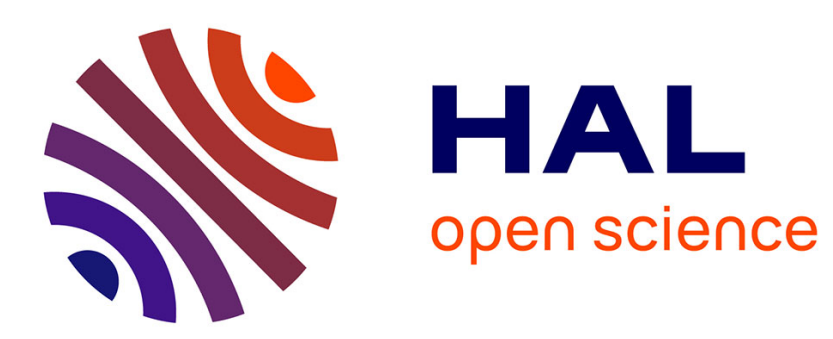

\title{
Tree species exhibit complex patterns of distribution in bottomland hardwood forests
}

Luben Dimov, Jim Chambers, Brian Lockhart

\section{To cite this version:}

Luben Dimov, Jim Chambers, Brian Lockhart. Tree species exhibit complex patterns of distribution in bottomland hardwood forests. Annals of Forest Science, 2013, 70 (8), pp.813-823. 10.1007/s13595013-0322-8 . hal-01201521

\section{HAL Id: hal-01201521 \\ https://hal.science/hal-01201521}

Submitted on 17 Sep 2015

HAL is a multi-disciplinary open access archive for the deposit and dissemination of scientific research documents, whether they are published or not. The documents may come from teaching and research institutions in France or abroad, or from public or private research centers.
L'archive ouverte pluridisciplinaire HAL, est destinée au dépôt et à la diffusion de documents scientifiques de niveau recherche, publiés ou non, émanant des établissements d'enseignement et de recherche français ou étrangers, des laboratoires publics ou privés. 


\title{
Tree species exhibit complex patterns of distribution in bottomland hardwood forests
}

\author{
Luben D. Dimov • Jim L. Chambers • \\ Brian Roy Lockhart
}

Received: 20 February 2013 / Accepted: 13 August 2013 /Published online: 19 September 2013

(C) INRA and Springer-Verlag France outside the USA 2013

\begin{abstract}
- Context Understanding tree interactions requires an insight into their spatial distribution.

- Aims We looked for presence and extent of tree intraspecific spatial point pattern (random, aggregated, or overdispersed) and interspecific spatial point pattern (independent, aggregated, or segregated).

- Methods We established twelve 0.64-ha plots in natural bottomland hardwood stands in the southeastern USA.

- Results Spatial point pattern analyses (Ripley's $K, L$, and $L_{12}$ ) indicated that, when species were combined, trees were frequently aggregated and less commonly overdispersed. Plots with larger trees were more likely to exhibit overdispersion, confirming a shift to this pattern as trees grow. The intraspecific pattern of cherrybark oak and water oak was either aggregated or random. Sweetgum was aggregated on all plots and always at smaller distances (less than $5 \mathrm{~m}$ ) than the two oak species. Intraspecific overdispersion was very rare. Interspecific
\end{abstract}

Handling Editor: Barry Alan Gardiner

Contribution of the co-authors LDD designed the experiment, carried out the field measurements, ran the analyses, and wrote the paper. JLC obtained funding and supervised the work. JLC and BRL coordinated the research project and provided reviews and feedback of the analysis and drafts of the manuscript. BRL helped with the field measurements.

Electronic supplementary material The online version of this article (doi:10.1007/s13595-013-0322-8) contains supplementary material, which is available to authorized users.

L. D. Dimov $\cdot$ J. L. Chambers

School of Renewable Natural Resources, Louisiana State University and Agricultural Center, Baton Rouge, LA, USA

L. D. Dimov $(\bowtie)$

Forestry, Ecology, and Wildlife Program, Alabama A\&M University, ARC Bldg Rm 101, Normal, AL 35762, USA

e-mail: Luben.Dimov@aamu.edu

B. R. Lockhart

U.S. Forest Service, Southern Research Station, Center for Bottomland Hardwoods Research, P.O. Box 227, Stoneville, Mississippi 38776, USA segregation among the two oak species was more commonly observed (six plots) than aggregation (one plot). Cherrybark oak and sweetgum were segregated at some scale on seven of the 12 plots and aggregated on only two plots.

- Conclusion The results from the analyses suggest that strong interspecific competition may result in segregation of trees from different species, while weaker intraspecific competition may lead to aggregations of conspecifics.

Keywords Univariate and bivariate tree spatial patterns

\section{Introduction}

The spatial distribution patterns of individual organisms are of frequent interest in ecological studies (Dale 2000). Early documented observations in the tropics (Wallace 1853) indicated that conspecific trees appear highly dispersed. Black et al. (1950) similarly observed that population densities of many Amazonian forest tree species are quite low with less than one individual per hectare. Janzen (1970) reported that adult tropical conspecific trees are not found in the immediate neighborhood of other adults where most seeds fall. Janzen then hypothesized that this results in tree distribution being more dispersed than clumped. He attributed this overdispersion to the effect of host-specific plant parasites and predators which exterminate the seeds and seedlings mostly at the places with higher density (i.e., near the seed producing adult trees). Other researchers also contended that a high degree of dispersion is likely a defense against predators on the seeds and seedlings (e.g., Connell 1971).

The development of spatial point pattern analysis techniques allowed statistical testing of many of the early observations and conjectures that were based on less sophisticated methods or on observations. Contrary to what scientists hypothesized in earlier decades, recent work (Condit et al. 2000) showed conclusively that conspecific trees of nearly all of the 
1,768 tropical species examined are clumped. The empirical data also indicated that larger conspecific trees are indeed less aggregated than smaller ones (but still aggregated, rather than overdispersed), supporting the notion of herbivores playing an important role in reducing conspecific aggregation at a young age in tropical species (Murphy and McCarthy 2012). Moreover, conspecific trees of rare species are more aggregated than those of common species (Hubbell 1979; Condit et al. 2000). Numerous other studies have also found clumping to be predominant among conspecific trees in tropical forests (e.g., Ashton 1969; Olagoke et al. 2013).

Analysis of the spatial distribution pattern of non-tropical trees species has not been as extensive. As in the tropics, however, aggregation is the most common type of conspecific spatial distribution pattern found. This was the case with ponderosa pine (Pinus ponderosa Dougl. ex Laws, White 1985) and with other conifers (Moeur 1993). In contrast to the high degree of dispersion Janzen (1970) found in young conspecific trees in the tropics, Dovčiak et al. (2001) determined that the smaller seedlings of white pine (Pinus strobus L.) are found farther from the seed source tree than the older seedlings. Based on this finding, Dovčiak et al. (2001) suggested that the conditions near the parent trees facilitate seedling establishment and survival; otherwise, the large seedlings would have also been present away from the tree. Work with temperate upland hardwoods found that trees of the same species are also aggregated, although some degree of overdispersion was observed for distances beyond $55 \mathrm{~m}$ (Aldrich et al. 2003). For most other distances, however, Aldrich et al. (2003) found that conspecific trees of all species are aggregated.

Tree spatial pattern is a crucial attribute of forest structure reflecting initial dispersal patterns, intra- and interspecific competition, influence of the microenvironment, interaction with other organisms, and stochastic events. The spatial pattern affects the distribution of leaves, litter fall, nectar, fruits, and seeds (Dale 2000). Many of the early studies of tree patterns used techniques with limited capabilities for detecting patterns of spatial distribution (i.e., quadrat methods, kernel estimation, and nearest-neighbor analysis), especially in comparison to some currently available methods. Some more recently developed and more complex techniques examine second-order effects, which are effects that relate to the spatial correlation or dependence, i.e., the $L(t)$ and $L_{12}(t)$ functions based on Ripley's $K$ (Dale 2000; Law et al. 2009). Additionally, most of the available studies investigate the spatial distribution patterns of trees from a single species, very often in isolation, and seldom examine more than one site. Use of a single study site is indicated as a problem by a number of authors (e.g., He and Duncan 2000).

Although much is known about species composition in bottomland hardwood forests of the southeastern United States, a significant gap exists in our knowledge about their inter- and intraspecific spatial distribution patterns within the stand. The current study examines the spatial distribution pattern in four bottomland hardwood stands in three southeastern states. This research also evaluates the pattern of (1) all plot trees regardless of their species, (2) three common and commercially important tree species-cherrybark oak (Quercus pagoda Raf.), water oak (Quercus nigra L.), and sweetgum (Liquidambar styraciflua L.) - and (3) the interspecific (bivariate) spatial patterns of each of the possible pairs of the three selected species. Bivariate spatial pattern analysis can reveal the presence of spatial aggregation (positive association) or segregation (negative association) between paired species (Goreaud and Pélissier 2003). Comparison between stands was not emphasized in this analysis, because our interest was in the underlying spatial distribution patterns that may be present in all of the studied bottomland hardwood forests.

A better understanding of the distribution patterns in bottomland hardwood forest communities is critical for advancement of their silviculture and management. Knowledge of the natural patterns is one of the first steps in better understanding stand dynamics and has the potential to provide further insight into intra- and interspecific competitive relationships within these species-rich forests. This should ultimately allow us to make better informed decisions about which competitors to remove during silvicultural treatments.

\section{Materials and methods}

\subsection{Study areas and measurements}

The study was carried out in four naturally regenerated bottomland hardwood stands. The stands are located in central Louisiana, northern Louisiana, southern Arkansas, and central Mississippi. The stands are assumed even-aged with mean age of 70 years estimated from annual ring count of basal tree sections of one to three overstory red oak trees (genus Quercus, subgenus Erythrobalanus) and had a $42 \%$ average proportion of oak basal area (range 13 to $73 \%$ ). The stand and plot characteristics are described in more detail in Dimov et al. $(2005,2008)$. Three square plots, $80 \mathrm{~m}$ on each side and minimum $10 \%$ red oak basal area (so it is representative of the forest cover in the region), were established in each stand to assess tree spatial distribution patterns. Plot selection procedures involved random selection from a pool of at least 12 preselected potential plots in the stand that had at least $10 \%$ red oak basal area. The orientation of the plot sides corresponded to the four cardinal directions. Only trees with diameters at breast height (dbh, $1.37 \mathrm{~m}$ above the ground) larger than $10.0 \mathrm{~cm}$ were measured. The collected data included tree dbh, species, and location on the plot using a local coordinate system. The slope on all plots 
was less than $1 \%$. The instruments used for mapping of tree locations were a laser hypsometer-rangefinder for the distances and a digital angle encoder for the horizontal angles (Laser Technologies Inc., Centennial, CO, USA). Mapping was carried out by measuring the angle from north and the horizontal distance to each tree from a point on the plot. These polar coordinates were converted to Cartesian coordinates (to the nearest $0.01 \mathrm{~m}$ ) for analysis. Tree diameters were measured with a diameter tape to the nearest millimeter, distances to the nearest centimeter, and horizontal angles to the nearest $0.01^{\circ}$.

\subsection{Data analysis}

The purpose of point pattern analysis, as related to tree distribution, is to determine if there is any systematic arrangement of the tree locations or if they are distributed at random. If they are not randomly distributed, they can be either aggregated (also referred to as clumped or clustered) or overdispersed (also referred to as hyperdispersed or regularly dispersed). Combinations of the different distribution patterns are also possible, i.e., trees can be randomly distributed at a certain scale, while at other scales they may exhibit aggregation, and at still other scales, they can be overdispersed.

In our analysis, we used second-order (local) properties, and we examined univariate patterns (patterns of one type of points, e.g., conspecific trees) and bivariate patterns (e.g., distribution of individuals from one species in relation to the individuals of another species). Second-order properties refer to the spatial patterns in subregions of the mapped area. Types of analyses of second-order properties include the nearestneighbor distance analysis, which assesses the distance from each tree to its nearest first, second, $\ldots, k^{\text {th }}$ order tree neighbor, and the $K$ function (Ripley 1981), also referred to as Ripley's $K$. A transformation of the $K$ function, called $L$ function, and the approaches based on the $K$ function are among some of the more widely used techniques for univariate and bivariate point pattern analysis (Dale 2000).

We calculated the $K$ function with the equation

$$
\widehat{K}(t)=\frac{A}{n^{2}} \sum_{i} \sum_{j} \frac{I_{t}}{w_{i j}}
$$

where $A$ is the plot area, $n$ is the number of trees on the plot, $t$ is a distance used as a radius of a circle around each tree within which the trees are counted, $I_{t}$ is an indicator function which is 1 if $d_{i j} \leq t$ and 0 if $d_{i j}>t\left(d_{i j}\right.$ is the distance between the $i$ th and $j$ th trees), and $w_{i j}$ is the weight. The purpose of assigning weights is for edge correction. Their use reflects the uncertainty that, for a tree close to the edge of the plot, there may be another tree outside the plot boundary that is closer to it than any of the mapped trees within the plot. We calculated the weights $w_{i j}$ with the equations:

$\left.w_{i j}=1-\cos ^{-1}\left(e / d_{i j}\right) / \pi\right)$;

$w_{i j}=1-\left[\cos ^{-1}\left(e_{1} / d_{i j}\right)+\cos ^{-1}\left(e_{2} / d_{i j}\right)+\pi / 2\right] / 2 \pi ;$ and $(3)$

$w_{i j}=1-\left[2 \cos ^{-1}\left(e_{1} / d_{i j}\right)+2 \cos ^{-1}\left(e_{2} / d_{i j}\right)\right] / 2 \pi$,

where $e$ is the distance from tree $i$ to the nearest boundary, and $e_{1}$ and $e_{2}$ are the distances between tree $i$ and the two nearest boundaries. Equation 2 is used when the distance $d_{i j}$ is greater than the distance $e$ between tree $i$ and the nearest boundary. Equation 3 is used when the distance from tree $i$ to the nearest plot corner (in a rectangular plot) is smaller than the distance $d_{i j}$. Otherwise, when the distance from tree $i$ to the nearest plot corner (in a rectangular plot) is greater than the distance $d_{i j}$, Eq. 4 is used.

For the univariate (intraspecific) spatial pattern analysis, we used the $L$ function, which represents the spatial pattern at various scales and is based on a transformation of the $K$ function that linearizes $K(t)$, stabilizing its variance, and results in $L(t)$ having an expected value of zero under the assumption of homogeneous Poisson process (a type of stochastic process):

$\widehat{L}(t)=\sqrt{\frac{\widehat{K}(t)}{\pi}}-t$

Plotting $L(t)$ against $t$ allowed us to examine for presence of spatial patterns at different scales. The spatial distribution pattern of the trees when $L(t)=0$ is termed complete spatial randomness (CSR). Under CSR, tree distribution follows a homogeneous Poisson process over the study region. Values of $L(t)>0$ suggest aggregation (i.e., the trees appear to be more clumped than what may be expected under CSR), while an $L(t)<0$ indicates overdispersion (i.e., the trees are more scattered or regularly spaced than what might be expected under CSR). The significance of the difference of $L(t)$ from 0 was examined by comparison with confidence envelopes constructed through Monte Carlo simulations.

For the bivariate (interspecific) spatial pattern analysis, we used the function $L_{12}(t)$ (where 1 represents the first species and 2 represents the second species). $L_{12}(t)$ is a transformation of the $K_{12}(t)$ function:

$\widehat{L}_{12}(t)=\sqrt{\frac{\widehat{K}_{12}(t)}{\pi}}-t$ 
where the $K_{12}(t)$ function is a generalization of the $K(t)$ function for a bivariate process and is calculated as follows:

$$
\frac{\widehat{K}_{12}(t)=n_{2} \widetilde{K}_{12}(t)+n_{1} \widetilde{K}_{21}(t)}{n_{1}+n_{2}}
$$

where $n_{1}$ and $n_{2}$ are the number of individuals from species 1 and 2 , and $\widetilde{K}_{12}$ and $\widetilde{K}_{21}$ are determined by the formulas:

$$
\begin{aligned}
& \widetilde{K}_{12}(t)=\frac{A}{n_{1} n_{2}} \sum_{i=1}^{n_{1}} \sum_{j=1}^{n_{2}} \frac{I_{t, 12}}{w_{i j}} \\
& \widetilde{K}_{21}(t)=\frac{A}{n_{1} n_{2}} \sum_{i=1}^{n_{1}} \sum_{j=1}^{n_{2}} \frac{I_{t, 21}}{w_{i j}^{\prime}}
\end{aligned}
$$

where $I_{t, 12}$ and $I_{t, 21}$ are indicator functions equal to 1 if $d_{i j} \leq t$ and $b_{i j} \leq t$ respectively and equal 0 if $d_{i j}>t$ and $b_{i j}>t$ respectively $\left(d_{i j}\right.$ is the distance between the $i$ th tree of species 1 and the $j$ th tree of species $2, b_{i j}$ is the distance between the $i$ th tree of species 2 and the $j$ th tree of species 1 ), and $w_{i j}$ and $w^{\prime}{ }_{i j}$ are the weight associated with species 1 and 2, respectively.

We used plots of $L_{12}(t)$ against $t$ to represent the spatial association between species pairs for cherrybark oak, water oak, and sweetgum at various scales. Similar to the interpretation of $L(t)$, when $L_{12}(t)=0$, the two species are considered to be spatially independent of each other. If $L_{12}(t)>0$, the two species are positively associated (presence of positive dependence or aggregation) with each other, which is interpreted in ecology as an attraction effect (Goreaud and Pélissier 2003). For values of $L_{12}(t)<0$, the two groups are considered to be negatively associated (presence of negative dependence or segregation) with each other, interpreted in ecology as a repulsion effect (Goreaud and Pélissier 2003).The degree of aggregation and segregation is proportional to the magnitude of the difference from 0 . We used Monte Carlo simulations to evaluate if $L_{12}(t)$ was significantly different from 0 .

In summary, we used the $L$ function and Monte Carlo simulations to examine whether the spatial distribution pattern of (1) all trees, regardless of species, within each plot and (2) the three species cherrybark oak, water oak, and sweetgum on each plot, conformed to CSR at scales up to a $t=40 \mathrm{~m}$. This distance was equal to half the length of the plot side as recommended in the literature. We used the Microsoft Excel ${ }^{\circledR}$ add-in SpPack (Perry 2004), which uses its own random number generator. We carried out 101 simulations for all Monte Carlo tests. A summary of the application of summary statistics of spatial point patterns is available in Law et al. (2009), while a review of the way to fit ecological processes to observed patterns can be found in Detto and Muller-Landau (2013).

\section{Results}

The number of trees ranged from 309 to $614 /$ ha (Table 1). Tree distribution, when all species were combined, differed significantly from random at some scale on 11 plots: six plots had trees that were significantly aggregated; three plots had trees that were significantly overdispersed, and two plots had trees that were both aggregated and overdispersed at some scale (Table 2). Departure from CSR was not detected for any scale (i.e., the $L(t)$ function was enclosed within the confidence envelopes for all distances) on one plot (Fig. 1a). In contrast, aggregation $(L(t)$ above the upper envelope) was detected at scales of 0.0 to 1.5 and 9.0 to $40.0 \mathrm{~m}$ (Fig. 1b), and overdispersion $(L(t)$ below the lower envelope) was detected at distances between about 1.0 and $5.5 \mathrm{~m}$ (Fig. 1c). For the remaining distances, the pattern was random. With the exception of the three plots in the Mississippi forest stand, the remaining plots that exhibit aggregation were consistently aggregated at the shorter distances - from 0.5 to just over $1 \mathrm{~m}$. On some plots, aggregation was also detected at larger distances. On plots 1, 2, and 3 in Mississippi, aggregation was found only at distances greater than $2.5,4.0$, and $7.0 \mathrm{~m}$, respectively, and in all three plots, the scale of aggregation extended up to the maximum examined distance of $40 \mathrm{~m}$. Overdispersion at the small distances occurred starting from about 2.5 and extending to $5 \mathrm{~m}$. Four of the five plots exhibiting overdispersion were those with largest quadratic mean tree diameters (QMD, diameter of the tree with mean basal area) (Tables 1 and 2).

Table 1 Quadratic mean diameter (QMD) at breast height $(1.37 \mathrm{~m})$,

\begin{tabular}{|c|c|c|c|c|c|}
\hline $\begin{array}{l}\text { Location and plot } \\
\text { number }\end{array}$ & $\begin{array}{l}\text { QMD } \\
(\mathrm{cm})\end{array}$ & Sweetgum & $\begin{array}{l}\text { Cherrybark } \\
\text { oak }\end{array}$ & $\begin{array}{l}\text { Water } \\
\text { oak }\end{array}$ & $\begin{array}{l}\text { All } \\
\text { species }\end{array}$ \\
\hline
\end{tabular}
number of trees from three selected species, and total number of trees

\begin{tabular}{|c|c|c|c|c|c|}
\hline \multicolumn{6}{|c|}{ Central Louisiana } \\
\hline 1 & 34.3 & 84 & 69 & 17 & 309 \\
\hline 2 & 33.0 & 177 & 22 & 53 & 378 \\
\hline 3 & 34.7 & 109 & 67 & 33 & 347 \\
\hline \multicolumn{6}{|c|}{ Northern Louisiana } \\
\hline 1 & 28.6 & 206 & 30 & 30 & 519 \\
\hline 2 & 26.1 & 233 & 58 & 33 & 578 \\
\hline 3 & 26.0 & 239 & 36 & 14 & 594 \\
\hline \multicolumn{6}{|c|}{ Arkansas } \\
\hline 1 & 30.6 & 136 & 72 & 72 & 434 \\
\hline 2 & 27.9 & 105 & 38 & 61 & 405 \\
\hline 3 & 30.7 & 113 & 119 & 48 & 394 \\
\hline \multicolumn{6}{|c|}{ Mississippi } \\
\hline 1 & 24.8 & 386 & 39 & 17 & 614 \\
\hline 2 & 27.9 & 389 & 16 & 3 & 595 \\
\hline 3 & 27.5 & 281 & 17 & 3 & 544 \\
\hline
\end{tabular}
from all species on the twelve 0.64 ha sample plots 
Table 2 Distance intervals (in meters) at which trees of all species combined are completely spatially randomly (CSR) distributed, significantly aggregated (AG), or overdispersed (OD) based on the $95 \%$ confidence envelope calculated for the $L(t)$ function

\begin{tabular}{|c|c|c|c|}
\hline $\begin{array}{l}\text { Location and plot } \\
\text { number }\end{array}$ & AG & CSR & OD \\
\hline \multicolumn{4}{|l|}{ Central Louisiana } \\
\hline 1 & & - & $3.2-3.7,4.5-4.9$ \\
\hline 2 & & - & $1.0-5.5$ \\
\hline 3 & $0.8-1.2$ & - & $\begin{array}{l}1.9-5.8,6.1-6.4, \\
\quad 6.9-8.0\end{array}$ \\
\hline \multicolumn{4}{|l|}{ Northern Louisiana } \\
\hline 1 & $0.9-1.1$ & - & \\
\hline 2 & $0.3-1.5,9.0-40.0$ & - & \\
\hline 3 & & - & $4.4-5.0$ \\
\hline \multicolumn{4}{|l|}{ Arkansas } \\
\hline 1 & & All & \\
\hline 2 & $\begin{array}{c}0.5-1.5,6.5-6.7,10.3- \\
12.9,15.3-16.1\end{array}$ & - & \\
\hline 3 & $0.4-0.8$ & - & $2.7-4.9$ \\
\hline \multicolumn{4}{|l|}{ Mississippi } \\
\hline 1 & $4.0-40.0$ & - & \\
\hline 2 & $7.0-40.0$ & - & \\
\hline \multirow[t]{2}{*}{3} & $2.5-40.0$ & - & \\
\hline & 12 plots; $A G=8 \mathrm{CSR}=1$ & $\mathrm{D}=5$ & \\
\hline
\end{tabular}

An en dash in the CSR column indicates that the trees are randomly dispersed at all distance intervals that are not listed in the AG and OD columns. If tree distribution is CSR at all measured scales, the word "All" appears in that column

The $L(t)$ function for cherrybark oak, water oak, and sweetgum, when the species are examined individually, indicated that aggregation and CSR were the most common (Table 3; three representative plots on Fig. 2). Cherrybark oak exhibited aggregation on six of the 12 plots and CSR on the other six plots. The aggregation started at distances from $5 \mathrm{~m}$ on four plots and from $12 \mathrm{~m}$ on two plots and sometimes extended to distances up to $40.0 \mathrm{~m}$. The spatial distribution of water oak was similar to that of cherrybark oak. Two of the 12 plots contained only two water oak trees; consequently, they could not be used for calculating $L(t)$. Of the remaining ten plots, on six plots, the spatial distribution of water oaks was not significantly different from the random distribution expected under CSR while, on the remaining four plots, the water oak trees were aggregated. Aggregation in water oak on three of the plots was detected at distances starting at $6.0,10.0$, and $15.0 \mathrm{~m}$ while, on the fourth plot, aggregation was evident at even shorter distance (between 0.0 to $2.5 \mathrm{~m}$ ). Sweetgum was aggregated on all 12 plots. Additionally, sweetgum aggregation commonly started at distances that were mostly shorter than those observed in the oaks - generally less than $5.0 \mathrm{~m}$. There were no plots on which sweetgum was distributed randomly for all examined
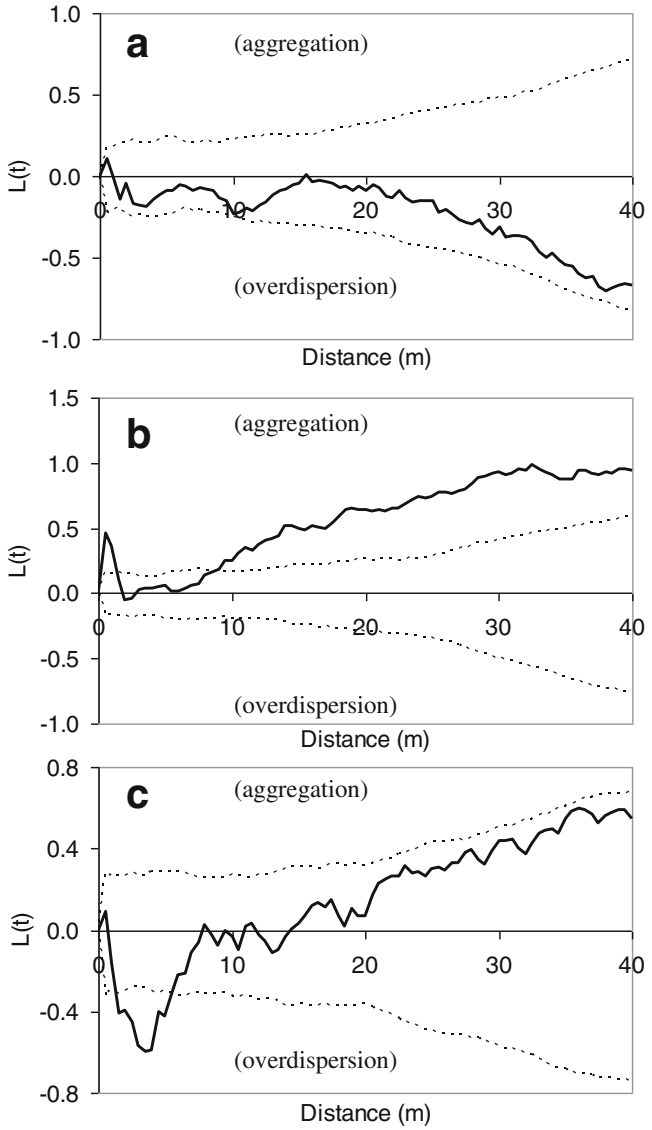

Fig. 1 Diagrams illustrating the three spatial distribution patterns that we observed, as indicated by the $L(t)$ function, an index of spatial pattern (thick line), against distance $t$. Shown are the patterns of the trees from all species that were present on these three particular plots. Complete spatial randomness (a) is present when $L(t)$ is within the $95 \%$ confidence envelope (thin lines). Aggregation at a certain distance is present when $L(t)$ extends above the upper $95 \%$ confidence envelope (b). Overdispersion is observed when $L(t)$ is below the lower envelope (c)

distances. Although overdispersion appeared to be present on one of the plots, it was only at very large distances $(37.8-40.0 \mathrm{~m})$.

The $L_{12}(t)$ function indicated that segregation was a more common pattern in the bivariate spatial distribution of the pairs of examined species (cherrybark oak, water oak, and sweetgum) than aggregation (Table 4; three representative plots on Fig. 3). There were ten plots with a sufficient number of cherrybark oak and water oak pairs to perform the bivariate spatial analyses for these two species. On six of these plots, significant segregation between the two species was apparent, while aggregation was detected on one plot. On the remaining three plots, the spatial distribution of each of the two species was independent from the distribution of the other. Segregation in a wide range of scales was frequently detected in the other two species combinations as well, with the cherrybark oak and sweetgum being segregated at some scale on seven of the 12 plots, aggregated on two plots, and distributed independently of each other on two plots. Both segregation and aggregation were 
Table 3 Distance intervals (in meters) at which trees of selected species are completely spatially randomly (CSR) distributed, significantly aggregated (AG), or overdispersed (OD) based on a 95\% confidence envelope

\begin{tabular}{|c|c|c|c|c|c|c|c|}
\hline \multirow[t]{2}{*}{ Location and plot number } & \multicolumn{2}{|l|}{ Cherrybark oak } & \multicolumn{2}{|l|}{ Water oak } & \multicolumn{3}{|l|}{ Sweetgum } \\
\hline & $\mathrm{AG}$ & CSR OD & AG & CSR OD & $\mathrm{AG}$ & CSR & OD \\
\hline \multicolumn{8}{|l|}{ Central Louisiana } \\
\hline 1 & & All & & All & $0.0-1.5,17.5-32.0,35.5-40.0$ & - & \\
\hline 2 & $12.0-40.0$ & - & & All & $0.0-0.5,7.0-40.0$ & - & \\
\hline 3 & & All & $6.0-30.0$ & - & $0.0-1.5,3.5-37.5$ & - & \\
\hline \multicolumn{8}{|l|}{ Northern Louisiana } \\
\hline 1 & & All & & All & $5.0-40.0$ & - & \\
\hline 2 & $5.5-12.0,14.5-17.0$ & - & $0.0-2.5,16.5-17.5$ & - & $0.0-40.0$ & - & \\
\hline 3 & $5.0-11.0$ & - & & All & $2.7-40.0$ & - & \\
\hline \multicolumn{8}{|l|}{ Arkansas } \\
\hline 1 & $12.0-14.5,16.0-26.0$ & - & $15.0-38.0$ & - & $2.0-13.0,14.5-16.5$ & - & \\
\hline 2 & & All & $10.0-40.0$ & - & $0.0-25.0$ & - & $37.8-40.0$ \\
\hline 3 & $5.5-40.0$ & - & & All & $0.0-3.5$ & - & \\
\hline \multicolumn{8}{|l|}{ Mississippi } \\
\hline 1 & $5.0-10.0,25.0-40.0$ & - & & All & $2.0-40.0$ & - & \\
\hline 2 & & All & $\mathrm{N} / \mathrm{A}^{\mathrm{a}}$ & $\mathrm{N} / \mathrm{A}$ & $3.0-40.0$ & - & \\
\hline \multirow[t]{2}{*}{3} & & All & N/A & N/A & $1.0-40.0$ & - & \\
\hline & 12 plots; $\mathrm{AG}=6 \mathrm{CSR}=$ & $=6 \mathrm{OD}=0$ & 10 plots; $\mathrm{AG}=4 \mathrm{CS}$ & $\mathrm{R}=6 \mathrm{OD}=0$ & 12 plots; $\mathrm{AG}=12 \mathrm{CSR}=0 \mathrm{OD}=$ & $=1$ & \\
\hline
\end{tabular}

An en dash in the CSR column indicates that the trees are randomly dispersed at all distance intervals that are not listed in the AG and OD columns. If tree distribution is CSR at all measured scales, the word "All" appears in that column

${ }^{a} \mathrm{~N} / \mathrm{A}$ represents a state of rarity $(<9$ individuals per plot) concerning water oak

detected at different scales on one plot in Arkansas (Table 4). The pairing of water oak and sweetgum resulted in the detection of segregation on four plots and aggregation on another four plots. On the remaining two plots, there was no spatial association present between water oak and sweetgum. Tree maps showing the locations of the three species are shown in the supplementary material (Supplementary Figures S1-S4).

\section{Discussion}

When carrying out interpretations and drawing conclusions from spatial point pattern analysis, we need to take into account that (1) forests are complex and multidimensional in nature but are being simplified to a two-dimensional pattern of points in this type of analysis, and (2) there are numerous possible variables that can affect spatial interactions among individual organisms to result in the observed pattern of spatial distribution, including time. The experimental design of this study allows us to examine the pattern but not the processes that drive it. Nevertheless, we discuss some of the processes that may be driving the observed pattern. We focus our discussion on the non-random patterns that we observed, so at spatial scales that are not specifically discussed, the trees are distributed randomly.

\subsection{Point pattern with all species combined}

Point pattern analysis of all species combined indicated presence of aggregation on most plots but also some overdispersion. On only one plot were the trees distributed randomly at all scales. Four of the five plots that exhibited overdispersion at some distance were the plots with the largest quadratic mean tree diameters (range from 24.8 to $34.7 \mathrm{~cm}$ ) compared with the rest of the plots. These were all plots in central Louisiana and plot 3 in Arkansas. The fifth plot, plot 3 in northern Louisiana, was an exception, as the mean tree diameter was among the smallest. The eight plots where aggregation was observed were primarily the plots where tree QMD was the smallest compared with the rest of the plots. Thus, in these bottomland hardwood stands, increasing average tree size seemed to be associated with a shift of tree spatial distribution from aggregation to overdispersion. Condit et al. (2000) also found that larger trees are indeed less aggregated than smaller ones. The shift from aggregation to overdispersion with increasing tree size is in agreement with the results from other studies (Moeur 1993; Ward et al. 1996). Moeur (1993) indicated that between-tree competitive interactions appear to drive spatial patterns of forest trees from clustering or aggregation toward regularity (overdispersion). Ward et al. (1996) detected a shift toward overdispersion of the spatial pattern of all size classes above $10 \mathrm{~cm}$ in diameter, over a period 

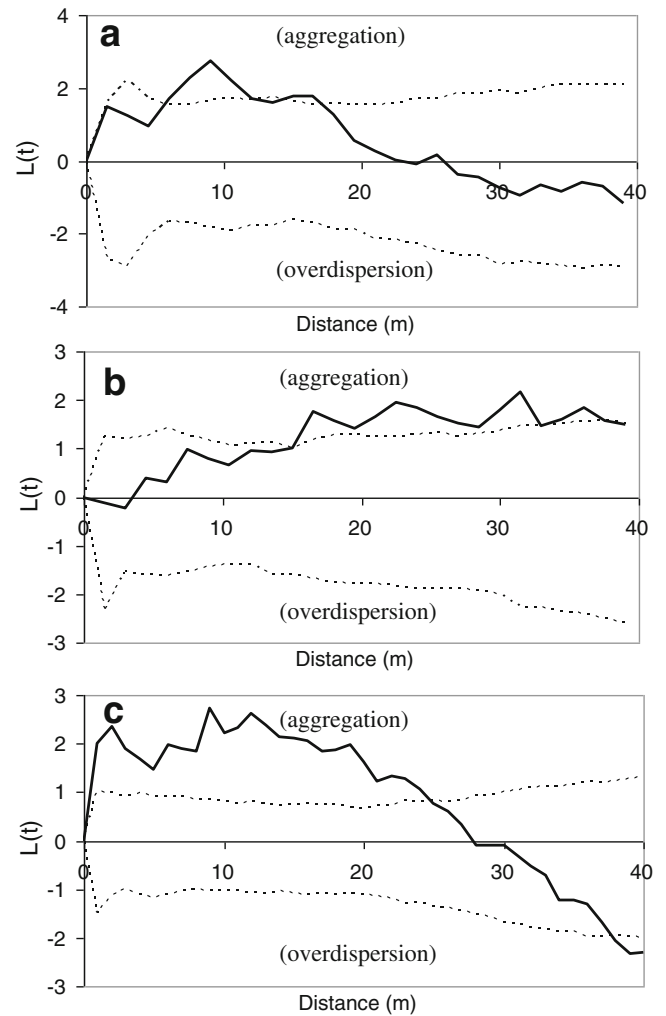

Fig 2 Representative sample plots of the spatial distribution patterns of cherrybark oak (a), water oak (b), and sweetgum (c) according to the $L(t)$ function, which is an index of spatial pattern (thick line) against distance $t$. Spatial aggregation is present when $L(t)$ is above the $95 \%$ confidence envelope (thin lines). Overdispersion is observed when $L(t)$ is below the lower envelope

of 50 years or more. Differences in the spatial pattern from plot to plot could result from different tree mortality dynamics. Pélissier (1998) indicated that large clumps of vegetation are found in areas disturbed by treefalls that create relatively large gaps while, in areas with standing tree mortality, there are no large gaps, and this leads to more regularity in the tree spatial distribution.

4.2 Intraspecific point pattern analysis for cherrybark oak, water oak, and sweetgum

Our analysis of the conspecific spatial patterns suggested that there were some fundamental differences in the spatial patterns of the two oak species and the pattern for sweetgum. On the plots where the number of trees of these species were sufficient for analysis, the cherrybark oak and water oak's spatial distributions were either equivalent to CSR, or aggregated at distances beyond $5 \mathrm{~m}$ in nearly all cases (with the exception of one plot where aggregation began at less than $1 \mathrm{~m})$. In contrast, sweetgum trees were generally clumped on all 12 plots, and aggregation was usually present at smaller distances. Aggregation in sweetgum may be a result of its propensity to regenerate from root sprouts and its relatively narrow crown, compared with the red oaks, which allows it to grow at greater densities.

Overdispersion was not a common intraspecific spatial pattern for the three chosen species. This is in agreement with the findings in a number of studies. Aldrich et al. (2003) similarly found that out of 23 tree species in a temperate hardwood forest in Indiana, most exhibit aggregation, while only four species exhibit overdispersion and that was at distances greater than $55 \mathrm{~m}$. Rebertus et al. (1989) found that Quercus laevis (turkey oak) on unburned Florida sandhills is slightly clumped to randomly dispersed. Other studies with hardwood species conducted in lowelevation hardwood forests in Virginia, concluded that the invasive tree-of-heaven (Ailanthus altissima Miller) has a tendency to be aggregated at a scale of $4-12 \mathrm{~m}$ on two sites and random on the remaining four sites (Call and Nilsen (2003). Another species, black locust (Robinia pseudoacacia L.), appeared to be clumped on all sites at a minimum distance of $1 \mathrm{~m}$ and maximum of $25 \mathrm{~m}$. Both the tree of heaven and black locust are prolific rootsprouters.

Some studies of coniferous species (Harrod et al. 1999; Dovčiak et al. 2001) found clumping in stands of ponderosa pine. Through stand reconstruction, Harrod et al. (1999) determined that an even larger degree of aggregation existed in historical ponderosa pine stands.

Studies in other geographic regions have obtained similar results regarding intraspecific tree spatial patterns. A large study encompassing many tropical forest conditions on two continents by Condit et al. (2000) indicated that clumping occurs in nearly all of the 1,768 tree species studied. From these species, 1,490 were significantly aggregated at scales of 0 to $10 \mathrm{~m} ; 1,759$ were aggregated at scales of 10 to $20 \mathrm{~m}$, and 1,730 were aggregated at scales of 20 to $30 \mathrm{~m}$. Aggregation is the prevailing pattern whether all trees $>1 \mathrm{~cm}$ dbh were considered, or only the trees with $\mathrm{dbh}>10 \mathrm{~cm}$ were included. Even when only large trees $(\mathrm{dbh}>30 \mathrm{~cm})$ were included, aggregation was again observed for most species, although aggregation intensity weakens with the increase in the minimal dbh threshold used. Other research reporting aggregated patterns of spatial distribution among conspecifics include Goreaud and Pélissier (1999; 2003). Results from a smaller number of studies do find some cases where aggregation and CSR are not the dominant patterns among conspecifics. Penttinen et al. (1992) found both Scots pine (Pinus sylvestris L.) and silver birch (Betula pendula Roth.) to be overdispersed. Other species exhibiting such shift from aggregation to overdispersion with increase in tree size include sand pine (Pinus clausa Vasey) (Laessle 1965), kahikatea (Dacrycarpus dacrydioides) (Duncan 1991), and Torrey pine (Pinus torreyana Parry ex Carr) (Wells and Getis 1999). 
Table 4 Distance intervals (in meters) at which trees from two species are distributed independently (ID), or exhibit significant interspecific aggregated (AG), or interspecific segregated (SG) based on a $95 \%$ confidence envelope

\begin{tabular}{|c|c|c|c|c|c|c|c|c|c|}
\hline \multirow[t]{2}{*}{ Location and plot number } & \multicolumn{3}{|c|}{ Cherrybark oak versus water oak } & \multicolumn{3}{|c|}{ Cherrybark oak versus sweetgum } & \multicolumn{3}{|c|}{ Water oak versus sweetgum } \\
\hline & $\mathrm{AG}$ & ID & SG & $\mathrm{AG}$ & ID & SG & $\mathrm{AG}$ & ID & SG \\
\hline \multicolumn{10}{|l|}{ Central Louisiana } \\
\hline 1 & & All & & & - & $1.0-3.0,4.5-15.8$ & $\begin{array}{l}\text { 16.5-22.5, } \\
28.5-30.0\end{array}$ & - & \\
\hline 2 & & - & $21.0-30.0$ & & All & & $22.7-40.0$ & - & \\
\hline 3 & & - & $\begin{array}{l}7.8-10.5,13.1-15.5 \\
20.7-22.5\end{array}$ & & - & $\begin{array}{l}3.8-4.3,7.0-8.5 \\
\quad 9.4-10.6\end{array}$ & $7.6-30.0$ & - & \\
\hline \multicolumn{10}{|l|}{ Northern Louisiana } \\
\hline 1 & & All & & $26.3-28.2,28.6-30.0$ & - & & & All & \\
\hline 2 & & - & $5.1-6.4$ & $30.3-40.0$ & - & & & - & $7.8-40.0$ \\
\hline 3 & & All & & & - & $14.2-36.5$ & & - & $6.2-30.0$ \\
\hline \multicolumn{10}{|l|}{ Arkansas } \\
\hline 1 & & - & $2.0-3.4,6.2-34.2$ & & All & & & - & $1.0-4.0$ \\
\hline 2 & & - & $17.7-21.3$ & $14.5-30.2$ & - & $3.0-6.7$ & & - & $\begin{array}{l}1.5-4.7 \\
22.4-27.0\end{array}$ \\
\hline 3 & & - & $2.7-7.0,9.5-10.6$ & & - & $0.0-5.6$ & & All & \\
\hline Mississippi & & & & & - & & & & \\
\hline 1 & $19.0-30.0$ & - & & $10.0-40.0$ & - & & $\begin{array}{l}0.0-4.0 \\
\quad 6.6-30.0\end{array}$ & - & \\
\hline 2 & $\mathrm{~N} / \mathrm{A}^{\mathrm{a}}$ & N/A & N/A & & - & $3.5-25.2$ & N/A & N/A & N/A \\
\hline \multirow[t]{2}{*}{3} & $\mathrm{~N} / \mathrm{A}$ & N/A & N/A & & - & $6.2-30.0$ & N/A & N/A & N/A \\
\hline & \multicolumn{3}{|c|}{10 plots; $A G=1 \mathrm{ID}=3 \mathrm{SG}=6$} & \multicolumn{3}{|c|}{12 plots; $\mathrm{AG}=4 \mathrm{ID}=2 \mathrm{SG}=7$} & \multicolumn{3}{|c|}{10 plots; $\mathrm{AG}=4 \mathrm{ID}=2 \mathrm{SG}=4$} \\
\hline
\end{tabular}

An en dash in the CSR column indicates that the trees are randomly dispersed at all distance intervals that are not listed in the AG and OD columns. If tree distribution is CSR at all measured scales, the word "All" appears in that column

${ }^{a} \mathrm{~N} / \mathrm{A}$ represents a state of rarity $(<9$ individuals per plot) for water oak

4.3 Interspecific point pattern analyses for cherrybark oak, water oak, and sweetgum

Aggregation was not a predominant spatial distribution pattern in the bivariate spatial pattern analysis of species pairs composed of cherrybark oak, water oak, and sweetgum, although some bispecific aggregations did occur. The prevailing distribution pattern between the cherrybark oak and water oak species pair and between the cherrybark oak and sweetgum species pair was segregation. While there was an equal number of plots indicating presence of either aggregation or segregation (i.e., positive or negative spatial association) between the water oak and sweetgum species pair, segregation was still a relatively frequent spatial pattern.

The prevalence of aggregation of conspecific trees, and of segregation among trees from different species, may indicate a higher level of interspecific competition relative to intraspecific competition. Such patterns may result from the competitive exclusion of one of the species from the habitat on which the other species is better suited to thrive. For microhabitats where both species are equally well adapted, factors like initial density, height growth pattern, crown growth dynamics
(Clatterbuck and Hodges 1988), and stand disturbance history will likely also exert an influence on the future bivariate spatial distribution patterns. The prevalence of aggregation of conspecifics and segregation of heterospecifics underlines the importance of examining more than just one plot in studies of tree spatial patterns.

Duncan (1991) suggested that repulsion between individual trees of two different species is not a result of competitive interspecific interaction but simply a way of avoiding such competition. Assuming fairly homogeneous site conditions (most of the sites in the current study lacked topographic variability and the slope was always less than $1 \%$ ), adequate seed availability, and adequate growing conditions for all three species, it can be argued that habitat partitioning is likely a result of severe interspecific competitive interactions at an early stage of stand development. This argument is supported by Jiří et al. (2004), who found greater mortality of common beech (Fagus sylvatica L.) in dense patches of silver fir (Abies alba Mill.), which would result in interspecific spatial segregation in the future stand composition. An example of bivariate spatial pattern affected by disturbances was presented by Rebertus et al. (1989), who determined that, after repeated 

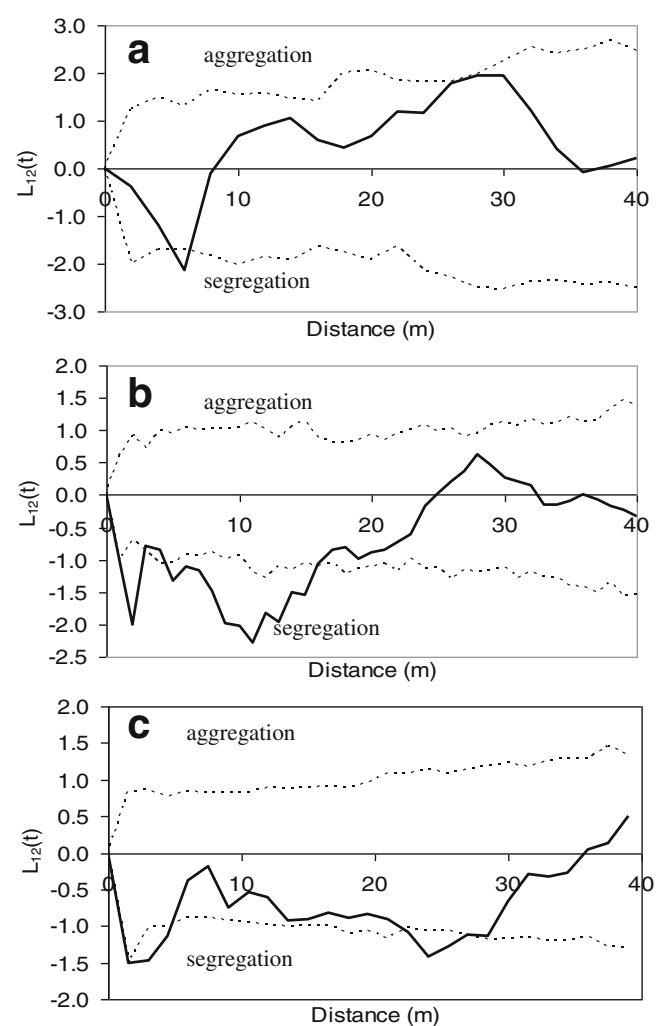

Fig. 3 Representative sample plots of the interspecific spatial distribution patterns of cherrybark oak and water oak (a), cherrybark oak and sweetgum (b), and water oak and sweetgum (c) according to the $L_{12}(t)$ function, which is an index of spatial independence (thick line) against distance $t$. Spatial aggregation is present when $L_{12}(t)$ is above the $95 \%$ confidence envelope (thin lines). Spatial segregation between the two populations is observed when $L_{12}(t)$ is below the lower envelope. When $L_{12}(t)$ is within the envelope the two populations are considered to be distributed spatially independently of each other

fires, a segregated pattern emerges between turkey oak $(Q$. laevis (Walt.) and longleaf pine (Pinus palustris (Mill.). The oaks are left in clumps that are well separated from longleaf pines. The pines cause substantial oak mortality in their neighborhood by creating "hot spots," areas of greater fire intensity and temperature due to the accumulated leaf litter under the pines.

The interspecific tree spatial segregation reported in the current study contrasts with the findings of a number of other studies. Martens et al. (1997) found strong aggregation of trees from two species at scales of 2 to $4 \mathrm{~m}$ on a semi-arid woodland in New Mexico. An overall positive spatial association was also found between tree-of-heaven and black locust on four out of six plots at minimum distances of 2.0 and $9.0 \mathrm{~m}$ (Call and Nilsen 2003). Lack of interspecific spatial aggregation was presented by Duncan (1991) for a mixed Podocarp stand in New Zealand, where no spatial dependence between two studied species was present.

With the development of spatial point pattern analysis techniques, many of the earlier observations (Wallace 1853;
Black et al. 1950; Janzen 1970) of high degrees of dispersion of forest trees have gradually given way to the statistically supported view that conspecific trees species actually appear to be aggregated in clumps. The validity of this notion has been corroborated for both tropical, upland temperate, and, with the current study, bottomland temperate forests. Explanations for the observed high frequency of aggregation in plant communities could be the patchiness of the suitable habitat (e.g., soil nutrient variability in patches) or better light conditions when trees regenerate in canopy gaps. Other possible reasons include the lack of good seed dispersal and survival of seeds at large distances from the seeding trees (Ashton 1969), seedling germination being most successful near adult plants (Hubbell 1979; Eccles et al. 1999), spatial variation of fire intensity (Rebertus et al. 1989) and other endogenous and exogenous stand disturbances, and positive or mutualistic interactions between plants (Eccles et al. 1999).

Random patterns in tree distribution may be related to either homogeneous site conditions or to heterogeneous site conditions associated with the ability of a species to tolerate and thrive in a wide range of environmental conditions. Cases of overdispersion may result where competition leads to regularity in the spacing through interspecific repulsion (Laessle 1965) and is sometimes observed at a later stage in stand development following the clumped and random distributions (Moeur 1993; Ward et al. 1996; Aldrich et al. 2003). Evidence from the current study suggests that, as average tree size increases, the spatial distribution pattern of the trees as a whole, regardless of species, may shift from aggregation to overdispersion. Interspecific competition among cherrybark oak, water oak, and sweetgum may have been intense and resulted in segregation, possibly after occupation of a limited resource by the more competitive species on a particular microsite. Spatial distribution of cherrybark oak and water oak was characterized by CSR and mostly large clumps, while sweetgum always exhibited aggregation at smaller scales. The aggregation of sweetgum at these scales may possibly be a result of root sprout regeneration and the inherently narrow crowns allowing greater tree densities.

If the observed overall segregation of trees from different species is a result of strong, or unequal, or asymmetric interspecific competition, and if the aggregation of conspecifics is due to weaker, or possibly equal or symmetric intraspecific competition, we can make some general management recommendations. We assume a thinning operation aimed at increasing the growth of the residual trees and at maintaining a diverse species mixture. If under such scenario a forester has a choice of removing one of two equally strong competitors of a crop tree, removal of the competitor from a different species should be preferred. This is because strong interspecific competition would generally result in mortality of the weaker competitor.

The observed patterns may also have implications in planting mixed forest stands. For the three species examined in detail 
in this study, it appears that conspecific trees should be planted in aggregations that are at least partially spatially separated from the other species. This would reduce the heavy interspecific competition and subsequent competitive exclusion of most trees from the less competitive species. However, such configuration may also reduce the positive "trainer" effect (positive in terms of quality timber production) of the weaker competitors on the more competitive species. Our conclusions and recommendations should be considered applicable only to the studied forest ecosystems. They are situations where the removal of one species may be detrimental to another species from the same trophic level, e.g., in dry environments where one tree species may increase the available moisture for another tree or shrub species through hydraulic lift.

Acknowledgments We thank Dr. Andy Ezell from the Department of Forestry at Mississippi State University, Richard Smith from the Noxubee National Wildlife Refuge, Mississippi, Dr. John Adams from the School of Forestry at Louisiana Tech University, Alan Boyd from Willamette Industries, Inc., Alan Boyd, Jake Floyd and Jim Scarborough from the USDA Forest Service, Tom Woods from the Louisiana Department of Wildlife and Fisheries, Jim Hefley from Resource Management Service, Inc. in Arkansas, and consulting forester Jewel Willis from Willis \& Taylor Forestry Consultants \& Land Management LLC in Louisiana. These individuals helped with finding suitable study sites, collecting data and samples, and logistical issues. Erica Stelzer, Joy Young, and many undergraduate students from the School of Renewable Natural Resources at Louisiana State University and the Department of Forestry at Mississippi State University helped with field work. We thank Thomas Dean, Steve Meadows, Kenny Rose, and three anonymous individuals who provided helpful reviews of earlier drafts.

Funding Partial funding for this project was provided by the McIntireStennis Cooperative Forestry Act. In-kind support was provided by Mississippi State University, Noxubee National Wildlife Refuge, Willamette Industries Inc., Resource Management Service Inc., the Department of Forestry at Mississippi State University, and the Thistlethwaite Family.

\section{References}

Aldrich PR, Parker GR, Ward JS, Michler CH (2003) Spatial dispersion of trees in an old-growth temperate hardwood forest over 69 years of succession. For Ecol Manag 180:475-491

Ashton PS (1969) Speciation among tropical forest trees: some deductions in light of recent evidence. Biol J Lin Soc 1:155-196

Black GA, Dobzhansky T, Pavan C (1950) Some attempts to estimate species diversity and population density trees in Amazonian forests. Bot Gaz 111:413-425

Call LJ, Nilsen ET (2003) Analysis of spatial patterns and spatial association between the invasive tree-of-heaven (Ailanthus altissima) and the native black locust (Robinia pseudoacacia). Am Midl Nat 150: $1-14$

Clatterbuck WK, Hodges JD (1988) Development of cherrybark oak and sweet gum in mixed, even-aged, bottomland stands in central Mississippi, U.S.A. Can J For Res 18:12-18

Condit RC, Ashton PS, Baker P, Bunyavejchewin S, Gunatilleke S, Gunatilleke N, Hubbell SP, Foster RB, Itoh A, LaFrankie JV, Lee
HS, Losos E, Manokaran N, Sukumar R, Yamakura T (2000) Spatial patterns in the distribution of tropical tree species. Science 288: $1414-1418$

Connell JH (1971) On the role of natural enemies in preventing competitive exclusion in some marine animals and in rain forest trees. In: den Boer PJ, Gradwell GR (eds) Dynamics of populations. Proceedings of the Advanced Study Institute on Dynamics of Numbers in Populations, Oosterbeek, The Netherlands. Wageningen, Pudoc, The Netherlands, pp 298-312, Center for agricultural publishing and documentation

Dale MRT (2000) Spatial patterns analysis in plant ecology. Cambridge University Press, Cambridge, United Kingdom, 326p

Detto M, Muller-Landau HC (2013) Fitting ecological process models to spatial patterns using scalewise variances and moment equations. Am Nat 181:E68-E82

Dimov LD, Chambers JL, Lockhart BR (2005) Spatial continuity of tree attributes in bottomland hardwood forests in the southeastern USA. For Sci 51:532-540

Dimov LD, Chambers JL, Lockhart BR (2008) Five-year radial growth of red oaks in mixed bottomland hardwood stands. For Ecol Manag 225:2790-2800

Dovčiak M, Frelich LE, Reich PB (2001) Discordance in spatial patterns of white pine (Pinus strobus) size-classes in a patchy near-boreal forest. J Ecol 89:280-291

Duncan RP (1991) Competition and the coexistence of species in a mixed Podocarp stand. J Ecol 79:1073-1084

Eccles NS, Esler KJ, Cowling RM (1999) Spatial pattern analysis in Namaqualand desert plant communities: evidence for general positive interactions. Plant Ecol 142:71-85

Goreaud F, Pélissier R (1999) On explicit formulas of edge effect correction for Ripley's $K$-function. J Veg Sci 10:433-438

Goreaud F, Pélissier R (2003) Avoiding misinterpretation of biotic interactions with the intertype $K_{12}$-function: population independence vs. random labeling hypotheses. J Veg Sci 14:681-692

Harrod RJ, McRae BH, Hartl WE (1999) Historical stand reconstruction in ponderosa pine forests to guide silvicultural prescriptions. For Ecol Manag 114:433-446

He FL, Duncan RP (2000) Density-dependent effects on tree survival in an old-growth Douglas fir forest. J Ecol 88:676-688

Hubbell SP (1979) Tree dispersal, abundance, and diversity in a tropical dry forest. Science 203:1299-1309

Janzen DH (1970) Herbivores and the number of tree species in tropical forests. Am Natur 104:501-528

Jiř́ D, Št'astná P, Hara T, Šrůtek M (2004) Neighborhood interactions and environmental factors influencing old-pasture succession in the Central Pyrenees. J Veg Sci 15:101-108

Laessle AM (1965) Spacing and competition in natural stands of sand pine. Ecology 46:65-72

Law R, Illian J, Burslem DFRP, Gratzer G, Gunatilleke CVS, Gunatilleke IAUN (2009) Ecological information from spatial patterns of plants: insights from point process theory. J Ecol 97:616-628

Martens SN, Breshears DD, Meyer CW, Barnes FJ (1997) Scales of above-ground and below-ground competition in a semi-arid woodland detected from spatial pattern. J Veg Sci 8:655-664

Moeur M (1993) Characterizing spatial patterns of trees using stemmapped data. For Sci 39:756-775

Murphy SJ, McCarthy BC (2012) Evidence for topographic control of tree spatial patterning in an old-growth, mixed mesophytic forest in southeastern Ohio. USA J Torrey Bot Soc 139:181-193

Olagoke AO, Bosire JO, Berger U (2013) Regeneration of Rhizophora mucronata (Lamk.) in degraded mangrove forest: lessons from point pattern analyses of local tree interactions. Acta Oecol 50:1-9

Pélissier R (1998) Tree spatial patterns in three contrasting plots of a southern Indian tropical moist evergreen forest. J Trop Ecol 14:1-16 
Penttinen A, Stoyan D, Henttonen HM (1992) Marked point processes in forest statistics. For Sci 38:806-824

Perry GLW (2004) SpPack: spatial point pattern analysis in Excel using Visual Basic for Applications (VBA). Environ Model Software 19: 559-569

Rebertus AJ, Williamson GB, Moser EB (1989) Fire-induced changes in Quercus laevis spatial pattern in Florida sandhills. J Ecol 77:638650

Ripley BD (1981) Spatial statistics. John Wiley and Sons, New York, 252p
Wallace AR (1853) A narrative of travels on the Amazon and Rio Negro. Haskell House Publishing Ltd, New York, 363p

Ward JS, Parker GR, Ferrandino FJ (1996) Long-term spatial dynamics in an old growth deciduous forest. For Ecol Manag 83:189-202

Wells ML, Getis A (1999) The spatial characteristics of stand structure in Pinus torreyana. Plant Ecol 143:153-170

White AS (1985) Presettlement regeneration patterns in a southwestern ponderosa pine stand. Ecology 66:589-594 